\title{
Design of smart home control system based on ZigBee Technology
}

\author{
Zou En ${ }^{1,2}$, Huo Qing ${ }^{2}$,Huang Shuihong ${ }^{2}$,Chen Shengchuang ${ }^{1}$
}

(1. College of zhujiang. South China Agricultural University. Guangzhou 510900, P.R.China.

2.College of Engineer. South China Agricultural University. Guangzhou 510642, P.R.China.

Keyword: ZigBee network; intelligent home; STC12C5A60S2 microcontroller; automatic control

\begin{abstract}
Based on the ZigBee technology, a hand-held portable intelligent home controlled terminal is designed on the basis of STC12C5A60S2 MCU, and make a detailed hardware design with floor control module. Main ZigBee (coordinator) module is connected with the handheld terminal and salved ZigBee (rounter) module communicate with the underlying chip so that lighting system, window treatments, fans system and air conditioning system are controlled. This paper focuses on designing closed-loop system by curtain and fan control systems. According to light intensity and real-time temperature, the system control brightness and temperature inside the home. The set of intelligent home model has been set up and run normally, passed the test system better able to communicate within $15 \mathrm{~m}$, and system is easy to use and has good practicability.
\end{abstract}

Smart Home is a comprehensive use of power automation technology, network communication technology, automatic control technology, integrated home systems. Compared with traditional home, whether living comfort, convenience of work are promoted to a higher grade. Over the wireless network to a variety of devices in the home (lighting systems, window systems, air conditioning systems, fan systems, security systems, etc.) combine together by the terminal controller integrated management, in order to achieve safe, comfortable and eco-friendly living environment ${ }^{[1]}$.

Smart home on the market in general and the use of embedded linux system set up home systems connected to the Internet, real-time status of this program through the Internet for remote monitoring of home and the operation of the control system, but the development of technology is more complex, relatively high cost of the system hardware and software ${ }^{[2]}$. Another more common smart home control system to take wired networking systems, common network for the RS485 or power line carrier networks. Although RS485 transmission distance is longer, the network is relatively easy to achieve, but it will bring the cost of additional wiring and not exempt traditional wired wire loss. The power line carrier system will bring home a lot of unnecessary interference signal ${ }^{[3]}$. For current high cost of intelligent home networking, wired communications and other shortcomings, we propose a ZigBee-based ad hoc network technology, designed to STC12C5A60S2 for the master's hand-portable and easy intelligent home control terminal, commonly used to control home appliances focused design system and fan system curtain closed-loop control, according to light intensity and adjust the brightness and temperature in real-time temperature inside the home. The system model has passed the laboratory commissioning, furniture and equipment to meet the internal control requirements.

\section{Smart Home System Design}

Smart home systems, including handheld terminal controller, CC2530 Zigbee send master module, CC2530 ZigBee receiver module from the bottom MCU, stepper motor drive module, DC motor drive module, the temperature sensor module, light sensor module, clock module. It can be divided into two parts of the system in general: Communication with the main ZigBee modules and handset design from MCU and each floor control system. Handset menu system has a total of five layers, including individual control of each device and one-button setup mode. Individual control device includes lighting systems, window systems, fan systems and air conditioning systems. One-button setup mode includes work mode, work mode, rest mode and automatic mode devices. ZigBee wireless network responsible for sending the device information and transmission control 
information to the various devices, send the information via the handset button control command ZigBee node is connected to the main issue is completed. Node capture signal from a serial form and communication MCU, easily control lights, curtains, household electrical and other equipment. System control block diagram shown in Figure 1.

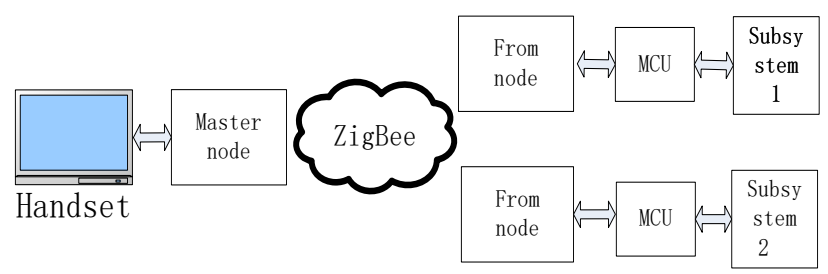

Fig.1 Diagram of control system

\section{System hardware design}

Hardware design include: handheld STC12C5A60S2 microcontroller module ${ }^{[4]}$., CC2530 Zigbee send master module, CC2530 ZigBee accepted part of the module from the bottom mcu, stepper motor drive module, DC motor drive module, the temperature sensor module, light sensor module, clock module.

\section{1 handset core control module}

Handset design core control module includes MCU minimum system microcontroller, with the clock DS1302, the storage module and a liquid crystal display circuit design AT24C02 12864. Where P0 as LCD data port; P1 and P2 port pin as part DS1302 and LCD output port, AT24C02 clock port and data port, respectively, then P1.7 and P1.2; 4 separate buttons and P3 port high four connections.

\section{2 curtain system control module}

Curtain system is mainly a closed loop control system since. In automatic mode, the real-time detection of the home through the inner illumination, after analog-digital conversion chip PCF8591 conversion, single-chip signal acquisition has been set based on the difference between the value of the acquired signals AD converted value controlled stepper motor rotation direction and step number, driving the curtains opening and closing, to ensure that the home is in a comfortable environment illumination; in the individual control mode, the handset settings menu of the opening of the curtains, send commands from the handset, ZigBee transmission network underlying stepper motor control MCU stepper motor driven rail, and then control the curtains pull together.

\section{System software design}

C51 language is used in Keil uVision4 environment commissioning. Software design mainly includes three parts. Handset menu system design, ZigBee node software configuration and the underlying MCU driver design.

\section{1 handset programming}

The main program flow chart shown in Figure 2, the system starts, first STC12C5A60S2 and LCD module initialization, the microcontroller initialization, including serial ports, timers, IO ports, etc. initialization; rear LCD initialization is complete, the handset display menu. Then enter a cycle, since the user must know the time to facilitate real-time control, there is a clock on the 3handset display; control the underlying parameters set, reads the value of AT24C02 to realize a key control home devices. Last call keyboard scanning, and real-time communication with ZigBee. 


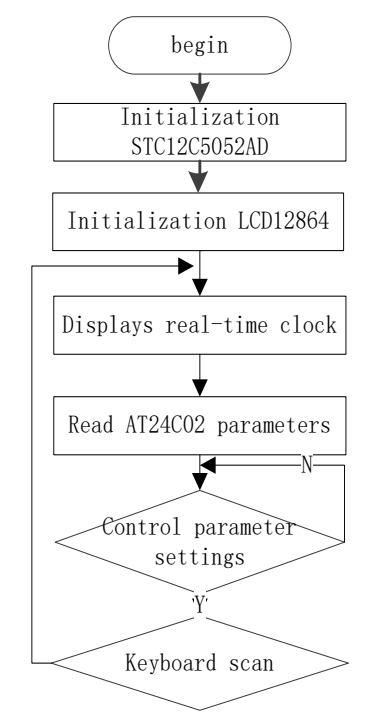

\subsection{ZigBee module software configuration analysis}

Fig.2 Flow chart of master program

In the smart home system, belong to the same network, set the value for the same PAN ID, guaranteed communication; baud rate is set to 9600, baud rate and the same MCU. There are three system nodes, any one of which is configured Coordinator, the remaining two for the router, a router between the Coordinator and a logically be seen as a wireless serial port. Wireless channel set as the default. 8, A main point in Figure node, B is able to transmit at any node from, but only one-way data transmission point B node, A point sends data to the A point. Since Zigbee network convenience, can well meet the requirements of home control.

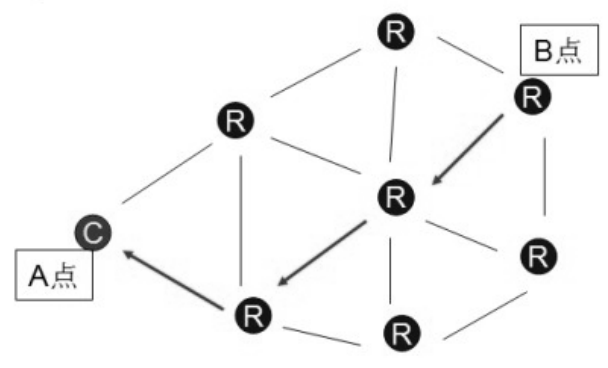

Fig.3 chematic diagram of ZigBee module

\section{System testing and analysis}

The success rate of smart home is the key to send and receive signals. Hence the need to test the transmission of packet loss rate, the following test, the total amount of a single test packet to 1000 ; packet transmission rate of 3 / s, pre-test to know if the packet transmission speed is greater than 8 / $\mathrm{s}, \mathrm{MCU}$ is not able to process data on the stack and cause a lot of packet loss, so the actual testing left margin, set 3 / s, this speed fully meet the actual project needs; to verify the loss ratio versus distance communications nodes, using method two ZigBee nodes at different spacing and calculate data on mass loss rate, the node spacing as 1,2,5,8,10,12 and $15 \mathrm{~m}$. Test spacing is determined based on: randomly selected two-spacing $1 \mathrm{~m}(0.2$ and 0.7$)$ to verify performance in a relatively short-range communication between nodes under; within $1 \sim 10 \mathrm{~m}$ range, every $5 \mathrm{~m}$ to determine a test point (5 and $10 \mathrm{~m}$ ), verify that the communication performance between nodes common application distance; within $10 \sim 20 \mathrm{~m}$ range, randomly selected every three test points (12, 14 and $18 \mathrm{~m}$ ), as a general adaptation from the home. Test data shown in Table 1. 
Table 1 relationship dropout rate and communication distance

\begin{tabular}{cccc}
\hline $\begin{array}{c}\text { Distance } \\
/ \mathrm{m}\end{array}$ & $\begin{array}{c}\text { The number } \\
\text { of packets } \\
\text { sent }\end{array}$ & $\begin{array}{c}\text { The ac- } \\
\text { tual } \\
\text { number } \\
\text { of } \\
\text { packets } \\
\text { received }\end{array}$ & $\begin{array}{c}\text { Packet } \\
\text { loss rate } \\
/ \%\end{array}$ \\
\hline 0.2 & 1000 & 1000 & 0 \\
0.7 & 1000 & 1000 & 0 \\
5 & 1000 & 998 & 0.2 \\
10 & 1000 & 996 & 0.4 \\
12 & 1000 & 978 & 2.2 \\
14 & 1000 & 969 & 3.1 \\
18 & 1000 & 960 & 4.0 \\
\hline
\end{tabular}

From the data, we can see at close range $(1-10 \mathrm{~m})$, packet loss rate is relatively low, at $0.5 \%$. Appears in the vicinity of 14 meters large packet loss rate, consistent with the low-power module communication link having a large irregularity, $14 \mathrm{~m}$ signal transition zone may be in communication unstable. Through testing, effective acceptance rate data of more than $96 \%$, to meet the general requirements of home control.

\section{Summary}

This design intelligent home control system based on ZigBee technology, and built the home model. Focused design a simple hand-held terminal, handheld terminal can be effectively controlled in real-time intelligent home commonly used equipment. The entire system can meet the control requirements. Test results show that the system meets the general requirements of home control, high reliability, low cost, in the field of intelligent home has a good prospect.

\section{Fund Project}

Guangdong Province, province, the higher education innovation and strong school project (4724) project funding.

\section{Reference}

[1] Studies Yu Wenjun, Ling Zhihao a smart home networking systems [J], Process Automation Instrumentation, 2011 (8): 56-59

[2] And implementation of Shen Bin, Zhang Guiqing Things smart home design based on [J], automation instruments, 2013 (2): 6-10

[3] Zhouxu Kun, Yang Lu crown ZigBee based smart home systems and PLC technology [J], ITS Applications, 2013,32 (9): 38-41.

[4]Wang Jing Science and Technology. STC12C5052AD MCU Device Handbook [z], 2009. 